\title{
Novel Bacteriophages Capable of Disrupting Biofilms From Clinical Strains of Aeromonas hydrophila
}

\author{
Mwila Kabwe ${ }^{1 *}$, Teagan Brown ${ }^{1}$, Lachlan Speirs ${ }^{1}$, Heng Ku' ${ }^{1}$, Michael Leach ${ }^{2}$, \\ Hiu Tat Chan ${ }^{3}$, Steve Petrovski ${ }^{4}$, Peter Lock ${ }^{5}$ and Joseph Tucci ${ }^{1 *}$ \\ 1 Department of Pharmacy and Biomedical Science, La Trobe Institute for Molecular Science, La Trobe University, Melbourne, \\ VIC, Australia, ${ }^{2}$ School of Rural Health, Monash University, Bendigo, VIC, Australia, ${ }^{3}$ Department of Microbiology, The Royal \\ Melbourne Hospital, Melbourne, VIC, Australia, ${ }^{4}$ Department of Physiology, Anatomy and Microbiology, La Trobe University, \\ Melbourne, VIC, Australia, ${ }^{5}$ La Trobe Institute for Molecular Science, La Trobe University, Melbourne, VIC, Australia
}

OPEN ACCESS

Edited by:

Krishna Mohan Poluri, Indian Institute of Technology Roorkee, India

Reviewed by:

Xiangmin Lin,

Fujian Agriculture and Forestry

University, China

Maria José Saavedra,

Universidade de Trás-os-Montes e

Alto Douro, Portugal

*Correspondence:

Mwila Kabwe

M.Kabwe@latrobe.edu.au Joseph Tucci

j.tucci@latrobe.edu.au

Specialty section:

This article was submitted to Antimicrobials, Resistance

and Chemotherapy,

a section of the journa

Frontiers in Microbiology

Received: 22 November 2019

Accepted: 28 January 2020

Published: 14 February 2020

Citation:

Kabwe M, Brown T, Speirs L, Ku H, Leach M, Chan HT, Petrovski S,

Lock P and Tucci J (2020) Novel Bacteriophages Capable of Disrupting

Biofilms From Clinical Strains

of Aeromonas hydrophila.

Front. Microbiol. 11:194.

doi: 10.3389/fmicb.2020.00194
The increase in global warming has favored growth of a range of opportunistic environmental bacteria and allowed some of these to become more pathogenic to humans. Aeromonas hydrophila is one such organism. Surviving in moist conditions in temperate climates, these bacteria have been associated with a range of diseases in humans, and in systemic infections can cause mortality in up to $46 \%$ of cases. Their capacity to form biofilms, carry antibiotic resistance mechanisms, and survive disinfection, has meant that they are not easily treated with traditional methods. Bacteriophage offer a possible alternative approach for controlling their growth. This study is the first to report the isolation and characterization of bacteriophages lytic against clinical strains of $A$. hydrophila which carry intrinsic antibiotic resistance genes. Functionally, these novel bacteriophages were shown to be capable of disrupting biofilms caused by clinical isolates of $A$. hydrophila. The potential exists for these to be tested in clinical and environmental settings.

Keywords: Aeromonas hydrophila, bacteriophage, genomics, biofilm, antimicrobial resistance

\section{INTRODUCTION}

Aeromonas hydrophila is a Gram-negative rod found in fresh water, brackish water, and mud in temperate climates (Batra et al., 2016). They are an established fish pathogen causing septicemia and ulcerative diseases (Chowdhury et al., 1990). Aeromonas spp. were first reported as infective agents in humans in 1951, and from that time have been seen as important human pathogens (Janda and Abbott, 2010). A. hydrophila implicated in human infections is usually mesophilic and grows optimally between 35 and $37^{\circ} \mathrm{C}$ (Janda and Abbott, 2010). Clinical infections may be a result of direct skin invasion from muddy water (Vally et al., 2004) or drinking contaminated water leading to local (gastritis, skin necrotizing infection) or systemic (peritonitis, sepsis, meningitis, respiratory, and hepatic) infections (Janda and Abbott, 2010; Igbinosa et al., 2012). Mortality in systemic infections may be as high as 46\% (Dryden and Munro, 1989).

The incidence of $A$. hydrophila has been correlated to warmer summer periods when the prevalence of this bacterium is increased in harvested rain water (Picard and Goullet, 1987) and in chlorinated or unchlorinated metropolitan water supplies (Burke et al., 1984a,b). 
Global climate change and population increases are expected to put greater pressures on water resources (DeNicola et al., 2015) and lead to increased investment in alternative sources such as rain harvesting (Ahmed et al., 2008). This is certainly the case in countries such as Australia, that is experiencing harsher summers and where use of recycled water for human consumption is not in vogue. A. hydrophila is estimated to be present in up to $33 \%$ of rain harvested water in Australia's major cities (Chubaka et al., 2018) and they are known to survive in chlorinated water by forming biofilms (Igbinosa et al., 2012). Biofilms provide bacterial cell-to-cell contact allowing for the transfer of genetic material that enhances the niche and increases resistance to stress and antibiotics (Talagrand-Reboul et al., 2017). Therefore, water originating from rain harvested tanks, municipal supplies, recreational settings such as swimming pools, and in the natural environment may serve as potential sources of infection.

Aeromonas spp. play a major role in the transfer of antibiotic resistance, making these organisms particularly problematic. They have been implicated as mediators of the transfer of antibiotic resistance markers between hospital and environmental strains (Varela et al., 2016), and are associated with innate multi-antibiotic resistance due to efflux pumps, inducible cephalosporinases, and inducible metallo beta lactamases (Azzopardi et al., 2011; Sinclair et al., 2016). Controlling A. hydrophila infection is therefore paramount as this organism threatens food security (by causing fish diseases and increasing their mortality) (Talagrand-Reboul et al., 2017) and human health (Neyts et al., 2000). Since the World Health Organization declaration that antibiotic resistance was a global emergency (World Health Organisation [WHO], 2014), alternatives for antibiotics have been actively researched (Czaplewski et al., 2016).

Bacteriophages, although discovered before antibiotics, have recently emerged as adjuncts and alternatives to antibiotics (Golkar et al., 2014). While temperate (Beilstein and Dreiseikelmann, 2008; Dziewit and Radlinska, 2016) and lytic (Chow and Rouf, 1983; Merino et al., 1990a,b; Shen et al., 2012; Jun et al., 2013; Anand et al., 2016; Wang et al., 2016; Le et al., 2018; Yuan et al., 2018) bacteriophages against A. hydrophila have been previously reported, these were isolated using environmental and fish pathogenic isolates of A. hydrophila. In the instances where host range was tested, their activity did not extend to clinical strains of A. hydrophila (Wang et al., 2016), that is, strains which were isolated from hospital patients suffering from $A$. hydrophila infections. Clinical strains of $A$. hydrophila have been shown to differ from environmental strains including those pathogenic in fish, in their production of virulence factors (Janda and Abbott, 2010), as well as other features. For instance, clinical strains are reported to restrict production of protease activity in favor of cytotoxicity and hemolysin production when temperatures increase from 30 to $37^{\circ} \mathrm{C}$ (Yu et al., 2007; Rasmussen-Ivey et al., 2016). Further, environmental strains can survive at temperatures as low as $4^{\circ} \mathrm{C}$ where clinical strain growth is inhibited (Mateos et al., 1993; Rasmussen-Ivey et al., 2016). To date there have been no lytic bacteriophages isolated that have demonstrated killing of clinical strains of $A$. hydrophila. This study screened for lytic bacteriophages against clinical strains of $A$. hydrophila associated with various human diseases. The isolated bacteriophages were characterized phenotypically and genomically, and functionally assessed for their capacity to degrade A. hydrophila biofilms.

\section{MATERIALS AND METHODS}

\section{Ethics Statement}

All methods were performed in accordance with the La Trobe University Ethics, Biosafety, and Integrity guidelines and regulations. Clinical isolates of $A$. hydrophila were obtained from specimen cultures as part of routine care. Informed consent was obtained from participants for their involvement and use of samples in this study. The study protocols were approved by the La Trobe University Ethics Committee, reference number: S17-111.

\section{Bacterial Growth and Strain Identification}

Aeromonas hydrophila bacteria was isolated from a deep wound infection (Strain AHB0117), a polymicrobial liver abscess on a background of cholangiocarcinoma (Strain AHB0148), a polymicrobial surgical site of infection (Strain AHB0116), diarrhea fecal samples (Strain AHB0139), and a scalp abscess due to trauma (Strain AHB0147), all de-identified. All strains were cultured in nutrient broth or agar (Oxoid, Australia) at $37^{\circ} \mathrm{C}$ aerobically. The bacterial strains were initially identified by Matrix Assisted Laser Desorption/Ionization - Time of Flight (MALDI-TOF; Bruker Daltonik, Germany). Conclusive identification was achieved by sequencing of the $16 \mathrm{~S}$ rRNA region (see Table 1 for PCR conditions), as well as screening for intrinsic antibiotic resistance markers endogenous to $A$. hydrophila (see below). The 16s rRNA amplicons were purified using QIAquick ${ }^{\circledR}$ PCR purification kits (Qiagen, Australia) and Sanger sequenced by the Australian Genome Research Facility (AGRF) in Queensland, Australia. The strains that were identified as A. hydrophila were used for subsequent bacteriophage screening.

\section{Antibiotic Sensitivity, Intrinsic Antibiotic Resistance, and CRISPR Characterization}

Antibiotic sensitivity of the A. hydrophila clinical strains used in this study was assessed using the VITEK ${ }^{\circledR} 2$ analyzer (bioMérieux, Australia), according to the manufacturer's instructions. Whole genome sequences of $A$. hydrophila strains published in the GenBank NCBI database were imported into CARD (Comprehensive Antibiotic Resistance Database) (Jia et al., 2017) and analyzed for genes coding antibiotic resistance. These genomes were also screened for CRISPR coded sequences using CRISPRFinder (Grissa et al., 2007). Identified sequences from (version 9.5.4) multiple strains were aligned in CLC genomic workbench and PCR primers designed from their conserved regions. The primer sequences and their PCR conditions are listed in Table 1 and amplicons were confirmed by sequencing (AGRF, Australia). Bacteriophage whole genome sequences were 
TABLE 1 | Primers and PCR reaction conditions for bacteria and antibiotic resistance characterization.

\begin{tabular}{|c|c|c|}
\hline Oligo name & Sequence $\left(5^{\prime}-3^{\prime}\right)$ & Cycling conditions \\
\hline \multirow[t]{2}{*}{$16 \mathrm{~S}$ rRNA } & U27F: AGAGTITGATCMTGGCTCAG & Hold: $95^{\circ} \mathrm{C}, 3 \mathrm{~min} 32$ cycles of $95^{\circ} \mathrm{C}, 30 \mathrm{~s} ; 60^{\circ} \mathrm{C}, 30 \mathrm{~s} ; 72^{\circ} \mathrm{C}, 90 \mathrm{~s}$ \\
\hline & U492R: AAGGAGGTGWTCCARCC & \\
\hline \multirow[t]{2}{*}{ CphA beta-lactamase class B } & FP: ACTCCATGGTCTATTTCGGG & Hold: $95^{\circ} \mathrm{C}, 10 \mathrm{~min} 35$ cycles of $95^{\circ} \mathrm{C}, 30 \mathrm{~s} ; 54^{\circ} \mathrm{C}, 30 \mathrm{~s} ; 72^{\circ} \mathrm{C}, 45 \mathrm{~s} ; 72^{\circ} \mathrm{C}, 10 \mathrm{~min}$ \\
\hline & RP: GTCTTGATCGGCAGCTTCAT & \\
\hline \multirow[t]{2}{*}{ FOX/MOX beta lactamase class $\mathrm{C}$} & FP: TACTATCGCCAGTGGACGCC & Hold: $95^{\circ} \mathrm{C}, 10 \mathrm{~min} 35$ cycles of $95^{\circ} \mathrm{C}, 30 \mathrm{~s} ; 54^{\circ} \mathrm{C}, 30 \mathrm{~s} ; 72^{\circ} \mathrm{C}, 45 \mathrm{~s} ; 72^{\circ} \mathrm{C}, 10 \mathrm{~min}$ \\
\hline & RP: TCCGCCGAGCTGGTCTTGAT & \\
\hline \multirow[t]{2}{*}{ OXA-12 beta lactamase class $D$} & FP: TाTCTCTATGCCGACGGCAA & Hold: $95^{\circ} \mathrm{C}, 10 \mathrm{~min} 35$ cycles of $95^{\circ} \mathrm{C}, 30 \mathrm{~s} ; 54^{\circ} \mathrm{C}, 30 \mathrm{~s} ; 72^{\circ} \mathrm{C}, 45 \mathrm{~s} ; 72^{\circ} \mathrm{C}, 10 \mathrm{~min}$ \\
\hline & RP: GTTGCCGTAGTCAAAACGGT & \\
\hline \multirow[t]{2}{*}{ Chloramphenicol resistance } & FP: ATCACCTGGTTCCTGTTCAG & Hold: $95^{\circ} \mathrm{C}, 10 \mathrm{~min} 35$ cycles of $95^{\circ} \mathrm{C}, 30 \mathrm{~s} ; 54^{\circ} \mathrm{C}, 30 \mathrm{~s} ; 72^{\circ} \mathrm{C}, 45 \mathrm{~s} ; 72^{\circ} \mathrm{C}, 10 \mathrm{~min}$ \\
\hline & RP: TACCGACGATGACCGCATAA & \\
\hline \multirow[t]{2}{*}{ MFS transporter } & FP: TTCTTCGTGGTGATGCCCAT & Hold: $95^{\circ} \mathrm{C}, 10 \mathrm{~min} 35$ cycles of $95^{\circ} \mathrm{C}, 30 \mathrm{~s} ; 53^{\circ} \mathrm{C}, 30 \mathrm{~s} ; 72^{\circ} \mathrm{C}, 45 \mathrm{~s} ; 72^{\circ} \mathrm{C}, 10 \mathrm{~min}$ \\
\hline & RP: GAAGATCAGCATCACCTGGA & \\
\hline \multirow{2}{*}{$\begin{array}{l}\text { Type I-E CRISPR-associate protein } \\
\text { Cas5/casD }\end{array}$} & FP: AACCCTACCTGCTACTATGG & Hold: $95^{\circ} \mathrm{C}, 10 \mathrm{~min} 35$ cycles of $95^{\circ} \mathrm{C}, 30 \mathrm{~s} ; 51^{\circ} \mathrm{C}, 30 \mathrm{~s} ; 72^{\circ} \mathrm{C}, 45 \mathrm{~s} ; 72^{\circ} \mathrm{C}, 10 \mathrm{~min}$ \\
\hline & RP: ATTCTGGTGACAACGGGCAA & \\
\hline
\end{tabular}

also screened for antimicrobial resistance genes (ARGs) and CRISPR as above.

\section{Bacteriophage Isolation and Host Range}

Wastewater and fishpond samples from Victoria, Australia, were screened for bacteriophages by enriching the samples with A. hydrophila. In brief, $100 \mu \mathrm{L}$ of log phase A. hydrophila was added to $10 \mathrm{~mL}$ of broth with $1 \mathrm{~mL}$ of filtered sample $(0.2 \mu \mathrm{m}$ cellulose acetate; Advantec, Australia). This enrichment was incubated for 4 days before filtration, and $10 \mu \mathrm{L}$ of this filtrate was then spotted onto a bacterial lawn of A. hydrophila on agar to screen for the presence of plaques. Host range testing was performed on five clinical strains of A. hydrophila.

\section{One-Step Growth Analysis}

Aeromonas hydrophila strains in exponential growth phase, collected by centrifugation at $12,000 \times g$ for $10 \mathrm{~min}$ and resuspended in fresh nutrient broth at a concentration of $0.6 \mathrm{U}\left(\mathrm{OD}_{600}\right)$, were used for the one step growth experiments (Wang et al., 2016). The strain AHB0147 was used for one-step growth experiments involving LAh1-LAh5 bacteriophages while LAh6-LAh10 bacteriophage one-step growth experiments were performed using the strain AHB0116. One hundred microliters of bacteriophage were added to $900 \mu \mathrm{L}$ of each A. hydrophila strain at a MOI of 0.01 and incubated at $4^{\circ} \mathrm{C}$ for $30 \mathrm{~min}$ to allow for adsorption. Adsorbed bacteriophage were collected by centrifugation at $12,000 \times g$ for $10 \mathrm{~min}$ and pellet resuspended in $50 \mathrm{~mL}$ of fresh nutrient broth. The mixture was incubated aerobically at $37^{\circ} \mathrm{C}$ and bacteriophages assayed using aliquots collected every $5 \mathrm{~min}$ by centrifugation at $12,000 \times g$ for $2 \min$ at $4^{\circ} \mathrm{C}$.

\section{Transmission Electron Microscopy}

Bacteriophage particles were visualized by Transmission Electron Microscopy using a JEOL JEM-2100 transmission electron microscope (TEM) at $200 \mathrm{kV}$. Bacteriophage lysate was adsorbed onto 400-mesh formvar and carbon coated copper grids (ProSciTech, Australia) for $1 \mathrm{~min}$. Grids were rinsed with
milli-Q water and adsorbed phage particles were negatively stained twice using 2\% (W/V) uranyl acetate (Sigma-Aldrich ${ }^{\oplus}$, Australia) for $20 \mathrm{~s}$. Excess stain was removed using filter paper and grids air dried for $30 \mathrm{~min}$. Images were captured on a Gatan Orius SC200D 1 wide-angle camera using the Gatan Microscopy Suite and Digital Micrograph Imaging software (version 2.3.2.888.0). The images obtained were further analyzed using ImageJ (version 1.8.0_112).

\section{Bacteriophage DNA Extraction}

All chemicals were purchased from Sigma-Aldrich ${ }^{\circledR}$ (Australia), unless stated otherwise. Concentrated bacteriophage stock (approximately $10^{11} \mathrm{PFU} \mathrm{mL}^{-1}$ ) was treated with $5 \mathrm{mmol} \mathrm{L}^{-1}$ of $\mathrm{MgCl}_{2}$ as well as RNase A and DNase I (Promega, Australia) to a final concentration of $10 \mu \mathrm{g} \mathrm{mL}$. The digest was incubated at room temperature for $30 \mathrm{~min}$ before polyethylene glycol precipitation at $4^{\circ} \mathrm{C}$ using PEG-8000 at $10 \%(\mathrm{w} / \mathrm{v})$ and sodium chloride $\left(1 \mathrm{gL}^{-1}\right)$. Precipitated virions were recovered by centrifugation at $12,000 \times g$ for 5 min to obtain a pellet which was then resuspended in $50 \mu \mathrm{L}$ nuclease free water (Promega, Australia). Viral proteins were digested with $50 \mu \mathrm{g} \mathrm{mL}-1$ of proteinase $\mathrm{K}, 20 \mathrm{mmol} \mathrm{L}^{-1}$ EDTA and $0.5 \%(\mathrm{v} / \mathrm{v})$ of sodium dodecyl sulfate for $1 \mathrm{~h}$ at $55^{\circ} \mathrm{C}$ to release phage DNA. Bacteriophage DNA was separated from proteins by addition of an equal volume of phenol-chloroform-isoamyl alcohol (29:28:1) and carefully collecting the aqueous phase after centrifugation at $12,000 \times g$ for $10 \mathrm{~min}$. An equal volume of isopropanol and overnight incubation at $-20^{\circ} \mathrm{C}$ was used to precipitate bacteriophage DNA. Bacteriophage DNA was then collected by centrifugation $(12,000 \times g$ for $5 \mathrm{~min})$ before washing in $70 \%$ ethanol, air-drying, and re-suspending in $30 \mu \mathrm{L}$ of nuclease free water (Promega, Australia).

\section{Bacteriophage Whole Genome Sequencing and in silico Analysis}

Nextera ${ }^{\circledR}$ XT DNA sample preparations kits were used to prepare phage DNA for sequencing according to the manufacturer's instructions. Whole genome sequencing of the prepared libraries 
was performed on an Illumina $\mathrm{MiSeq}^{\circledR}$ using a $\mathrm{MiSeq}^{\circledR}$ V2 300 cycle reagent kit. Sequence reads were imported into CLC genomics workbench (version 9.5.4) and assembled de novo. Open reading frames (ORFs) were predicted and translated using CLC genomics workbench (version 9.5.4). Translated ORFs were analyzed using BLASTP (Mount, 2007) and tRNAs and tmRNAs predicted using ARAGORN (Laslett and Canback, 2004) and tRNAscan-SE 2.0 (Lowe and Chan, 2016). Bacteriophage genomes were also analyzed for CRISPR sequences using the CRISPR database (Grissa et al., 2007). Whole genome alignments of isolated bacteriophages and those against other Aeromonas spp. (sourced from GenBank) were conducted and a phylogenetic tree constructed by neighbor joining method with 1000 bootstrap replicates in CLC genomics workbench (version 9.5.4). The bacteriophage genomes were also assessed by MAUVE plugin (Darling et al., 2004) in Geneious (version 11.0.5) ${ }^{1}$.

\section{Biofilm Degradation Assays}

The capacity to disrupt $A$. hydrophila biofilms was determined by growing $A$. hydrophila mono-biofilms in a 96 well polystyrene plate (Greiner bio-one, Australia). The 96 well plates were inoculated with $100 \mu \mathrm{L}$ of $10^{8} \mathrm{CFU} \mathrm{mL} \mathrm{m}^{-1} \log$ phase $A$. hydrophila in broth culture and a further $100 \mu \mathrm{L}$ of sterile broth added. The cultures were then incubated aerobically at $37^{\circ} \mathrm{C}$, shaking, for 4 days. Ten microliters of bacteriophage at a concentration of $10^{8} \mathrm{PFU} \mathrm{mL} \mathrm{mL}^{-1}$ was added to the established biofilms and for each experiment, heat inactivated (autoclaved) bacteriophage was used as a control to confirm that the effects on biofilm were the result of bacteriophage particles, rather than chemical residues or other matter in the preparation. Bacterial attachment was assayed according to Merritt et al. (2005). Briefly, plates were submerged in water to wash cells for $5 \mathrm{~min}$ before staining with $200 \mu \mathrm{L}$ of $0.1 \%$ crystal violet for $10 \mathrm{~min}$. The excess crystal violet was removed by submerging the plates in water for $5 \mathrm{~min}$. The stained adherent cells were then solubilized in $70 \%$ ethanol and the absorbance in each well determined (at a wavelength of $550 \mathrm{~nm}$ ) using a FlexStation 3 plate reader (Molecular devices, United States). Bacteriophages LAh7, LAh9, and LAh10 were tested on A. hydrophila strain AHB0116 biofilm whilst LAh1 was tested on biofilm formed by AHB0147.

\section{Viability of Biofilm}

Aeromonas hydrophila biofilms grown on glass slides were stained with $100 \mu \mathrm{L}$ of SYBR ${ }^{\circledR}$ gold (Eugene, OR, United States; $1 \mathrm{mg} \mathrm{mL}{ }^{-1}$ ) diluted in dimethyl sulfoxide (Sigma-Aldrich ${ }^{\circledR}$, Australia) and $3 \mu \mathrm{L}$ of $1 \mathrm{mg} \mathrm{mL}^{-1}$ propidium iodide (PI) in nuclease free water (Promega, Australia) for $30 \mathrm{~min}$ in the dark. The live/dead stained cells were mounted with $10 \mu \mathrm{L}$ Vectorshield ${ }^{\circledR}$ (Burlingame, CA, United States) on coverslips. The stained slides were visualized with an Olympus Fluoview Fv10i-confocal laser-scanning microscope (Olympus Life Science, Australia). PI stained DNA of membranecompromised cells red while SYBR Gold ${ }^{\circledR}$ stained DNA from both intact and membrane-compromised cells green.

${ }^{1}$ http://www.geneious.com/

\section{Statistical Analysis}

Statistical tests were used to assess the capacity of bacteriophages to break down biofilms from clinical strains of $A$. hydrophila. Firstly, the Shapiro-Wilk test was used to assess whether, for each individual bacteriophage, biofilm absorbance at $\mathrm{OD}_{550 \mathrm{~nm}}$ was normally distributed. As these data were found to be non-normally distributed, biofilm absorbance at $\mathrm{OD}_{550 \mathrm{~nm}}$ for each phage was summarized in terms of the median rather than the mean, with the full five-number summaries presented in side-by-side boxplots. The interquartile range (IQR) was also calculated. Due to the non-normality of the data, the biofilm absorbance at $\mathrm{OD}_{550 \mathrm{~nm}}$ for each bacteriophage was compared with that for every other phage using a nonparametric test - the Wilcoxon signed-rank test. $p$-values less than 0.05 were considered to be statistically significant. All statistical tests were performed in SPSS version 24 (SPSS Inc., United States).

\section{RESULTS}

\section{Antibiotic Resistance in Aeromonas hydrophila}

Five clinical isolates identified as A. hydrophila were screened for ARGs by PCR amplification, revealing intrinsic multi-antibiotic resistance. These included genes coding for chloramphenicol resistance (5/5), major facilitator superfamily efflux transporter (5/5), CphA class B beta lactamase (5/5), FOX/MOX class C beta lactamase (4/5), and OXA-12 class D beta lactamases (5/5) (Figure 1). All strains used in this study were susceptible to ciprofloxacin, cotrimoxazole, and gentamicin.

\section{Isolation of Novel Bacteriophages Against Clinical Strains of Aeromonas hydrophila}

Wastewater and pond samples collected from the cities of Bendigo and Melbourne, Victoria, Australia were screened for bacteriophages. Ten bacteriophages against five clinical strains of $A$. hydrophila were isolated. Of these, eight were Podoviridae (comprising five icosahedral and three elongated Podoviridae), one was a Siphoviridae and one was a Myoviridae virus. The novel bacteriophages were labeled LAh1-LAh10, with LAh1-LAh5 representing the icosahedral Podoviridae, LAh6, LAh8, and LAh9 representing the elongated version of the Podoviridae, while LAh7 and LAh10 were Siphoviridae and Myoviridae bacteriophages respectively (Figure 2). The elongated Podoviridae bacteriophages had capsid length $\approx 172 \pm 10 \mathrm{~nm}$, width $\approx 35 \pm 2 \mathrm{~nm}$ and tail length $\approx 18 \pm 1 \mathrm{~nm}$ while the icosahedral Podoviridae had capsid diameter $\approx 82 \pm 4 \mathrm{~nm}$ and tail $\approx 8 \pm 1 \mathrm{~nm}$. The Siphoviridae bacteriophages had capsid length and tail length of $\approx 44 \pm 3 \mathrm{~nm}$ and $\approx 232 \pm 13 \mathrm{~nm}$, respectively. Myoviridae bacteriophages had capsid diameter of $\approx 116 \pm 13 \mathrm{~nm}$ and tail length $\approx 183 \pm 5 \mathrm{~nm}$ (Figure 2). Specific features of the bacteriophages and their characteristics are summarized in Table 2 while their respective one-step growth curves are shown in Figure 3. 


\begin{tabular}{l|c} 
Antibiotic resistance markers & Aeromonas hydrophila strains \\
\hline & AHB0117 AHB0116 AHB0139 AHB0148 AHB0147 Negative \\
\hline CphA class B beta lactamase & \\
OXA-12 class D beta lactamase & \\
FOX/MOX class C beta lactamase & \\
MFS efflux pump & \\
Chloramphenicol resistance & \\
\hline
\end{tabular}

FIGURE 1 | PCR detection of antibiotic resistance markers in clinical strains of $A$. hydrophila used in this study. All resistance genes were present in all clinical strains except class C beta lactamase in AHB0117. The images presented here are taken from two separate gels, which are displayed in Supplementary Figures S1, S2. The white space between these images delineates sections that were cropped from different regions of the gels in Supplementary Figures S1, S2.

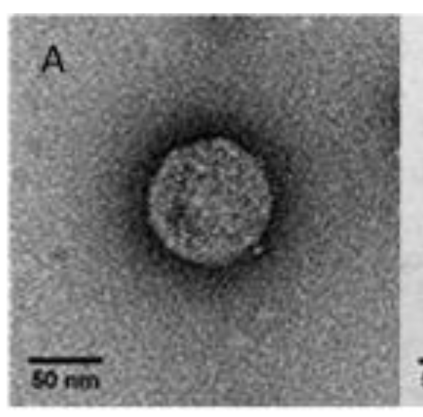

Capsid: $82 \pm 4 n m$ Tail: $8 \pm 1 \mathrm{~nm}$

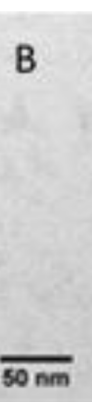

Capsid: $44 \pm 3 \mathrm{~nm}$ Tail: $233 \pm 13 \mathrm{~nm}$

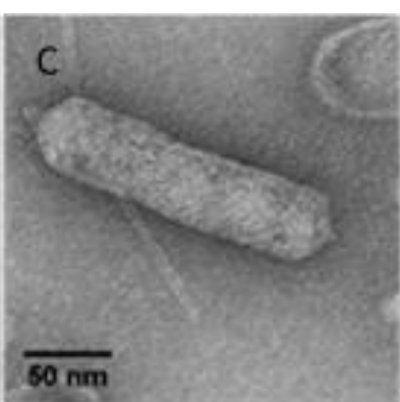

Capsid (L): $172 \pm 10 \mathrm{~nm}$ Capsid (W):35 $\pm 2 \mathrm{~nm}$ Tail:18 $\pm 1 \mathrm{~nm}$

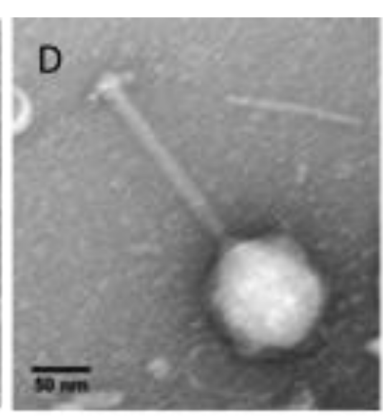

Capsid: $116.2 \pm 13 \mathrm{~nm}$ Tail:183.5 $\pm 5.1 \mathrm{~nm}$

FIGURE 2 | Transmission electron microscopy of representative bacteriophages from LAh1-LAh10. (A) Typical morphology of LAh1-LAh5 (icosahedral Podoviridae); (B) LAh7 (Siphoviridae); (C) typical morphology of LAh6, LAh8, and LAh9 (elongated Podoviridae); and (D) LAh10 (Myoviridae). All scale bar at $50 \mathrm{~nm}$.

TABLE 2 | LAh1-LAh10 genotypic and phenotypic characteristics.

\begin{tabular}{|c|c|c|c|c|c|c|c|c|c|c|c|c|}
\hline \multirow{2}{*}{$\begin{array}{l}\text { Phage } \\
\text { name }\end{array}$} & \multirow[t]{2}{*}{ Source } & \multirow[t]{2}{*}{ EM morphology } & \multirow{2}{*}{$\begin{array}{l}\text { Genome } \\
\text { size (bp) }\end{array}$} & \multirow[t]{2}{*}{ ORFs } & \multirow[t]{2}{*}{ GC\% } & \multicolumn{5}{|c|}{ Host range (bacterial strain) } & \multirow{2}{*}{$\begin{array}{c}\text { Number of } \\
\text { tRNAs }\end{array}$} & \multirow{2}{*}{$\begin{array}{l}\text { GenBank } \\
\text { accession }\end{array}$} \\
\hline & & & & & & АНB0148 & АHB0147 & АHB0139 & AHB0117 & AHB0116 & & \\
\hline LAh1 & Wastewater & Podoviridae & 42002 & 45 & 59.30 & No & Yes & No & No & No & 0 & MK838107 \\
\hline LAh2 & Wastewater & Podoviridae & 42008 & 45 & 59.30 & No & Yes & No & No & No & 0 & MK838108 \\
\hline LAh3 & Wastewater & Podoviridae & 42002 & 50 & 59.30 & No & Yes & No & No & No & 0 & MK838109 \\
\hline LAh4 & Wastewater & Podoviridae & 42002 & 52 & 59.30 & No & Yes & No & No & No & 0 & MK838110 \\
\hline LAh5 & Wastewater & Podoviridae & 41985 & 53 & 59.30 & No & Yes & No & No & No & 0 & MK838111 \\
\hline LAh6 & Fish pond & Podoviridae & 101437 & 165 & 42.30 & Yes & No & Yes & No & Yes & 21 & MK838112 \\
\hline LAh7 & Wastewater & Siphoviridae & 61426 & 75 & 61.90 & No & No & Yes & Yes & Yes & 0 & MK838113 \\
\hline LAh8 & Wastewater & Podoviridae & 97408 & 143 & 42.20 & Yes & No & Yes & No & Yes & 21 & MK838114 \\
\hline LAh9 & Wastewater & Podoviridae & 97988 & 147 & 42.40 & Yes & No & No & No & Yes & 18 & MK838115 \\
\hline LAh10 & Wastewater & Myoviridae & 260310 & 227 & 47.50 & No & No & Yes & No & Yes & 4 & MK838116 \\
\hline
\end{tabular}

\section{Whole Genome Sequencing of Bacteriophages LAh1-LAh10}

Illumina sequencing revealed novel and diverse genomes with several displaying a similar size of approximately 42,000 bp
(LAh1-LAh5). While the genomes of LAh1-LAh5 were the most similar to each other, specific differences were seen, and these resulted in non-synonymous amino acid changes (differences in their genomes and amino acid sequences are highlighted in 

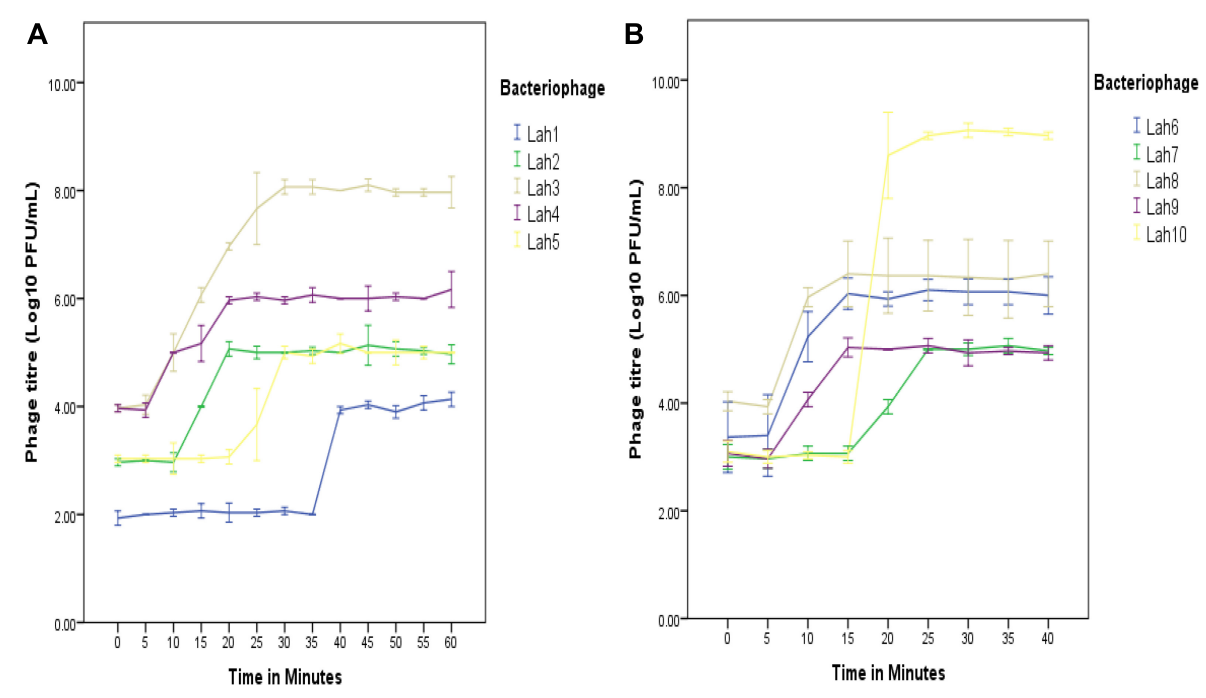

FIGURE 3 | One-step growth curves for A. hydrophila bacteriophages LAh1-LAh10 on two separate bacterial strains (depending on host range specificity). On the same host (A. hydrophila AHB0147), replication kinetics were different for LAh1-LAh5 (A). LAh6-LAh10 differed in their growth kinetics when grown on A. hydrophila strain AHB0116 (B). The standard errors of the mean are calculated from three independent experiments.

Table 3). Larger genomes were found in LAh7 (61,426 bp), LAh8 (97,408 bp), LAh9 (97,988 bp), and LAh6 (101,437 bp). LAh10 had the largest genome $(260,310 \mathrm{bp})$ which is the also the largest reported to date against $A$. hydrophila. The genomes for LAh1LAh10 were annotated and submitted to GenBank with accession numbers shown in Table 2. All bacteriophages had their genomes in a linear topology except LAh6 which had a circularly permuted genome. The number of ORFs varied with the genome size and ranged from 45 to 227 (Table 2). The GC\% content ranged from $42.2 \%$ in LAh8 to $61.9 \%$ in LAh7. While no bacteriophage showed presence of tmRNA in their genomes, tRNAs were present in 4/10 of the bacteriophages (Table 2). The number or type of tRNAs were not associated with genome size. LAh6 and LAh8 had the highest number of tRNAs at 21 each, followed by LAh9 with 18 tRNAs and LAh10 with 4 tRNAs. Therefore, the bacteriophages with a lower GC\% content had a higher number of tRNAs (Table 2). Bacteriophages LAh1-LAh5, and LAh7 did not have any tRNAs in their genomes. None of the bacteriophages isolated in this study had genes coding for putative CRISPR sequences, ARGs, toxins or chromosome integration genes in their genomes.

\section{Bacteriophage Phylogeny and Host Specificity}

Prior to this study there were 30 reported bacteriophages against Aeromonas spp. including eight against $A$. hydrophila which have had their genome completely sequenced. The 10 bacteriophages reported here are the first lytic bacteriophages to be isolated against clinical strains of $A$. hydrophila. The complete genome sequences of the previously isolated bacteriophages against Aeromonas spp. sourced from GenBank and those from this study were compared. Figure 4 reveals the clustering of bacteriophages against clinical strains of $A$. hydrophila forming two clusters among other bacteriophages isolated using A. hydrophila strains from the environment but further away from those against other Aeromonas species.

These differences among the isolated bacteriophage genomes were further analyzed by Mauve whole genome alignment of LAh1-LAh10 (Figure 5). The differences in the bacteriophage cluster of LAh1-LAh5 is detailed in Table 3 to highlight functional differences between these bacteriophages. For the cluster of bacteriophages LAh6, LAh8, and LAh9, the Mauve alignment showed the presence of a genetic segment (Blue colored colinear block in Figure 5) in the region of the putative tail fiber genes of bacteriophages that possibly contributed to their differences in host range. While similar in their genomes, LAh6 and LAh8 are able to lyse A. hydrophila strain AHB0139 that LAh9 is not (Table 2). The genome alignments show close homology between LAh1 and LAh5, and a diversity of nucleotide sequence between genomes of LAh7 and LAh10.

\section{Capacity of LAh1-LAh10 to Disrupt Aeromonas hydrophila Biofilms in vitro}

The capacity to disrupt $A$. hydrophila biofilms was analyzed quantitatively by evaluating the biofilm mass remaining after bacteriophage treatment and estimating the viability of the remnant biofilm. A representative bacteriophage from each morphological group was analyzed for capacity to disrupt biofilm. LAh1 was used as an example of icosahedral Podoviridae, LAh9 for the elongated Podoviridae, LAh7, a Siphoviridae, and LAh10 a Myoviridae. All biofilm experiments were performed using A. hydrophila bacterial strain AHB0116 that was lysed by all bacteriophages isolated here except for LAh1, in which case the host AHB0147 was used. In all cases, the biofilm mass was significantly reduced in bacteriophage treated compared to non-treated groups $(p<0.001)$. The untreated biofilm had a median (IQR) 
TABLE 3 | Differences in the genomes of bacteriophages LAh2-LAh5 compared to LAh1.

\begin{tabular}{|c|c|c|c|c|}
\hline Bacteriophage & Nucleotide change & Position & Non-synonymous amino acid change & Putative protein \\
\hline LAh2; LAh4 & $C>A$ & 1939 & $Z>K$ & Scaffolding protein \\
\hline LAh5 & $A>G$ & 8203 & $R>G$ & Hypothetical \\
\hline LAh5 & $\mathrm{G}>\mathrm{C}$ & 8205 & $R>G$ & Hypothetical \\
\hline LAh5 & Deletion (18 bp) & $8207 . .8224$ & R; P; S; R; TGA (STOP); S & Hypothetical \\
\hline LAh4 & $G>A$ & 14009 & $A>T$ & Tail fiber \\
\hline LAh2; LAh4 & $A>G$ & 15068 & $N>D$ & Tail fiber \\
\hline LAh3; LAh5 & $A>G$ & 15075 & $C>Y$ & Tail fiber \\
\hline LAh2 & Insertion 4 bp & $33001 . .33006$ & I and M (START) & DNA polymerase \\
\hline
\end{tabular}

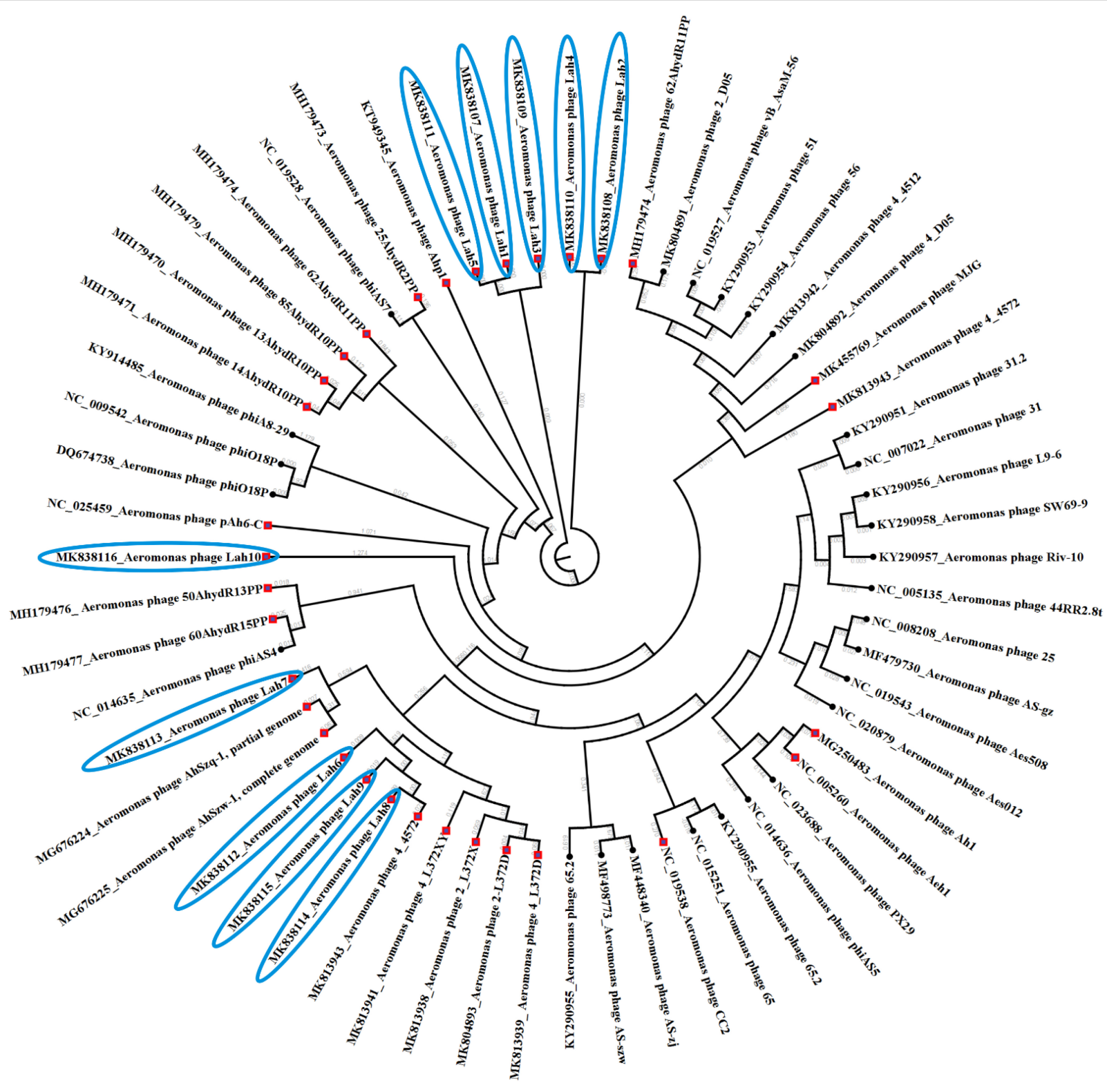

FIGURE 4 | Phylogenetic tree showing genetic relatedness of bacteriophages against Aeromonas species. All bacteriophages against $A$. hydrophila are indicated by red diamond nodes including those isolated in this study using clinical strains of $A$. hydrophila which have been highlighted in blue. 


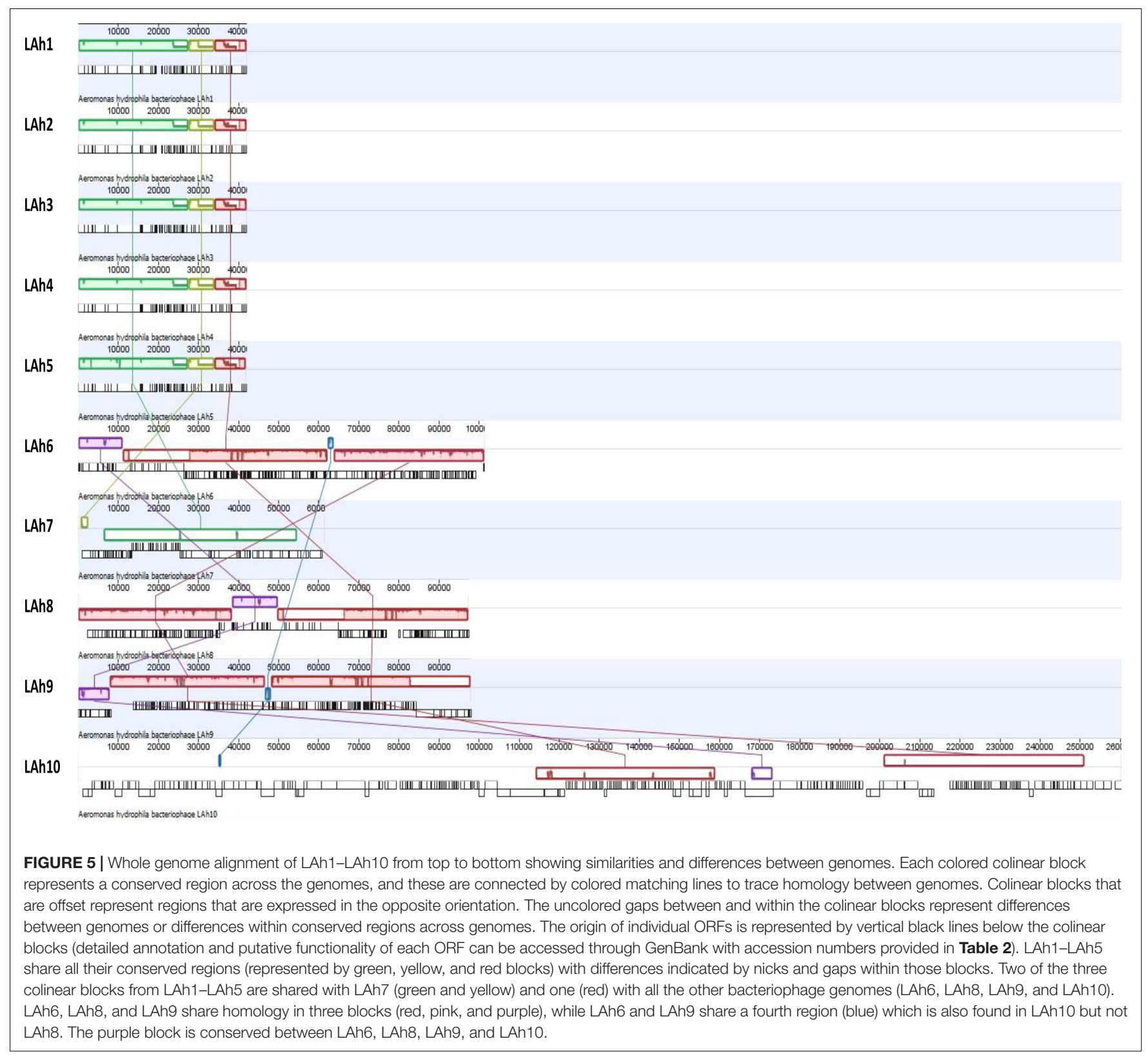

absorbance at $\mathrm{OD}_{550 \mathrm{~nm}}$ of $1.73(0.86)$ whilst the largest value for the remnant biofilm after bacteriophage treatment was 1.20 (0.27), $p<0.001$ (following treatment with LAh9). Treatment with LAh1 resulted in the lowest absorbance for the remnant biofilm [median (IQR) at $\mathrm{OD}_{550 \mathrm{~nm}}$ of $0.35(0.04)$ ], significantly lower $(p<0.001)$ than those treated with all the other bacteriophages. LAh7 and LAh10 had statistically similar $(p=0.58)$ remaining biofilm with absorbance of median (IQR) at $\mathrm{OD}_{550 \mathrm{~nm}}$ of $0.43(0.29)$ and $0.48(0.13)$, respectively (Figure 6). Of the bacteriophages tested on the A. hydrophila biofilms, those with higher GC\% content and lower numbers of tRNAs [LAh1 (59.30\%; 0), LAh7 (61.90\%; $0)$, and LAh10 (47.50\%; 4)] showed significantly greater capacity to degrade biofilms $(p<0.001)$ than that with lower
GC\% content and higher numbers of tRNAs [LAh9 (42.40\%; 18)] (Figure 6).

\section{Viability of Biofilm Treated With Bacteriophages}

The viability of the biofilm mass was investigated using SYBR Gold ${ }^{\circledR}$ and PI live/dead staining. Figure 7 shows cells fluorescing green (whole population of cells making up the biofilm) and red (dead, membrane-compromised cells). The icosahedral Podoviridae Bacteriophage LAh1 on host strain AHB0147 was used in the biofilm viability experiments. Figure 7 shows untreated biofilm with a sparse population of membrane-compromised cells (Figure 7B1) 


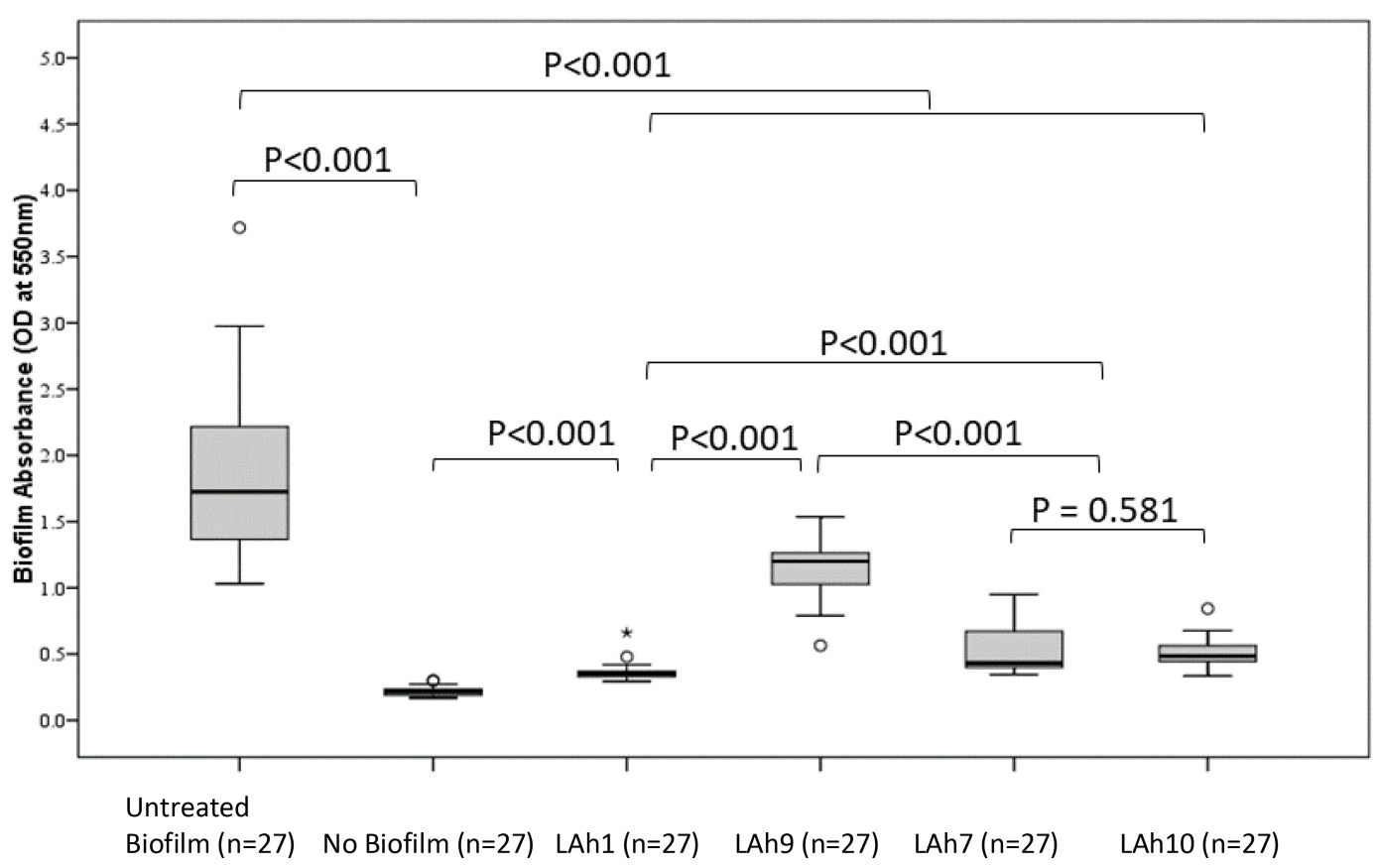

FIGURE 6 | Aeromonas hydrophila biofilm absorbance measurements after treatment with bacteriophages LAh1, LAh7, LAh9, and LAh10. Bacteriophages LAh7, LAh9, and LAh10 were tested on A. hydrophila strain AHB0116 biofilm whilst LAh1 was tested on biofilm formed by AHB0147. Bacteriophages with higher GC\% content and lower numbers of tRNAs [LAh1 (59.30\%; 0), LAh7 (61.90\%; 0), and LAh10 (47.50\%; 4)] showed significantly greater capacity to degrade biofilms $(p<0.001)$ than that with lower GC\% content and higher numbers of tRNAs [LAh9 (42.40\%; 18)]. * Is an extreme outlier.

compared to a dense total population (Figure 7B2). This indicated that cell population in the untreated biofilm was comprised of mostly membrane-intact cells. This was in contrast to the biofilms treated with bacteriophage (Figures 7A1,A2) in which the density was comparable between total population and membrane-compromised cells implying the cell population was mostly dead. In the bacteriophage treated biofilm, the total population and dead cells were both sparse. Treatment with heat inactivated (autoclaved) bacteriophage did not affect biofilm growth, indicating that Aeromonas biofilm disruption was the result of bacteriophage particles, and not other material in the preparation.

\section{DISCUSSION}

Increasing global temperatures have allowed a number of microorganisms to emerge as potential causes of disease (Aguirre and Tabor, 2008). A. hydrophila is one bacterial species benefiting from global warming with more clinical strains emerging (Azzopardi et al., 2011). These bacteria are usually resistant to first and second line antibiotic therapy involving beta-lactam drugs and third generation cephalosporins via mechanisms such as resistance genes and biofilm formation (Janda and Abbott, 2010). Bacteriophages, which have been suggested as an alternative to antibiotics, have been isolated against environmental and fish pathogen strains of $A$. hydrophila (Chow and Rouf, 1983; Merino et al., 1990a,b; Gibb and Edgell, 2007;
Shen et al., 2012; Jun et al., 2013; Anand et al., 2016; Wang et al., 2016; Le et al., 2018; Yuan et al., 2018; Bai et al., 2019; Cao et al., 2019; Kazimierczak et al., 2019). The host range of these bacteriophages, however, was not reported to extend to clinical strains. The current study is the first to report the isolation and characterization of bacteriophages lytic against clinical strains of $A$. hydrophila, all of which carry intrinsic antibiotic resistance markers. These bacteriophages (LAh1LAh10) displayed diversity in their morphology and genomic composition. The genomes of LAh1-LAh5 were the most similar to each other, yet specific differences were seen, and these resulted in non-synonymous amino acid changes. These changes may have contributed to the differences in growth kinetics observed between LAh1 and LAh5. Phylogenetic comparison between LAh1 and LAh10 and other Aeromonas bacteriophages revealed that LAh1-LAh10 clustered separately to those lytic for environmental strains of $A$. hydrophila and to bacteriophages against other species of Aeromonas.

Aeromonas hydrophila has been shown to thrive in water storage tanks and swimming pools as biofilms (Julia Manresa et al., 2009; Chubaka et al., 2018). The persistence of $A$. hydrophila in such environments has been implicated in several diseases such as diarrhea, sepsis and necrotizing fasciitis (Janda and Abbott, 2010). Bacteria growing in biofilm communities are more difficult to control than planktonic ones and A. hydrophila in particular is resistant to treatment with antibiotics and disinfectants such as chlorine (Donlan and Costerton, 2002; Janda and Abbott, 2010). Bacteriophages, which have been shown to be safe in clinical applications (Malik et al., 2017; Dedrick et al., 2019; 

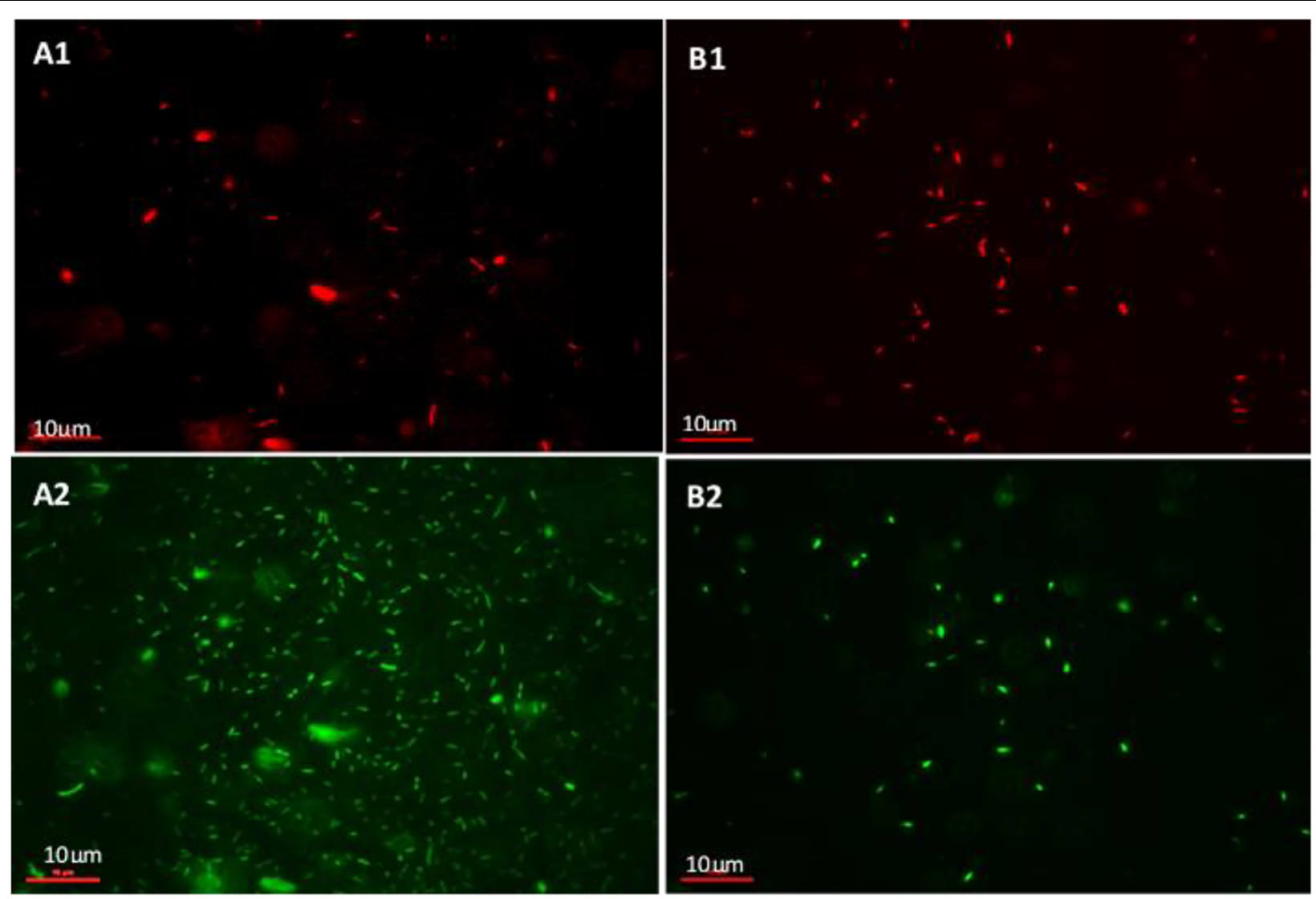

FIGURE 7 | Live/dead staining of $A$. hydrophila biofilm using propidium lodide (PI) and SYBR gold ${ }^{\circledR}$. (A1,A2) show untreated $A$. hydrophila biofilm on a glass slide. (A1) PI stained (dead) cells and (A2) cells stained with SYBR gold ${ }^{\oplus}$ (total population of cells). (B1,B2) A. hydrophila biofilm on a glass slide treated with bacteriophage LAh1 for 60 min. (B1) PI stained (dead) cells and (B2) cells stained with SYBR gold ${ }^{\circledR}$ (total population of cells).

Nir-Paz et al., 2019; Schmidt, 2019) may provide a useful solution to controlling this bacterium in a changing climate. The bacteriophages isolated and tested in this study were able to significantly reduce the $A$. hydrophila biofilm mass after $24 \mathrm{~h}$ of treatment. While these bacteriophages as well as others are active against biofilms (Hansen et al., 2019; Saha and Mukherjee, 2019), the factors associated with their efficacy have not been fully elucidated. The bacteriophages isolated in this study were diverse in morphology, genome content and organization. Their Podoviridae, Siphoviridae, or Myoviridae morphology was not associated with their capacity to disrupt a biofilm. The size of the genome and physical size of the bacteriophages was also not associated with their biofilm disruptive capabilities. However, bacteriophages in this study with a low GC\% content and with a higher number of tRNAs had a lower biofilm disruptive efficacy. While we did not assess the GC\% content of the A. hydrophila strains used for the biofilm assays here, the GC\% of $A$. hydrophila published genomes ranged from 60.2 to $61.3 \%$ (Chan et al., 2015; Tan et al., 2015a,b; Forn-Cuni et al., 2016a,b; Moura et al., 2017). Assuming our bacterial strains had similar content, then it would appear that bacteriophages in our study which matched more closely the GC\% of the bacteria were significantly more successful in degrading biofilms. Bacteria growing in biofilms will slow down their metabolism (Donlan and Costerton, 2002), and this factor may have a greater impact on those bacteriophages that carry their own tRNAs. It is important, however, to highlight that the sample of bacteriophages we assayed in our study was small, and the number of those with and without tRNAs was even smaller. Therefore, more concrete experimental data and extensive sampling is required before definitive conclusions can be drawn from such observations.

While others report that bacteriophage GC\% content was related to GC\% content of host bacteria (Xia and Yuen, 2005) and that presence of tRNAs was characteristic of more virulent bacteriophages (Bailly-Bechet et al., 2007), in our study there was no apparent relationship between host range and GC\% content or number of tRNAs present in bacteriophage genomes. In the bacteriophages isolated here, those with lower GC\% content had higher numbers of tRNAs, similar to findings in a study of bacteriophages against Aeromonas salmonicida subsp. Salmonicida (Vincent et al., 2017). This may not be surprising if we assume that the genomes of $A$. hydrophila used here have a similar GC\% content to those previously published [60.2-61.3\% (Chan et al., 2015; Tan et al., 2015a,b; Forn-Cuni et al., 2016a,b; Moura et al., 2017)] and that while bacteriophage genomes evolve to match the GC\% of their hosts (Xia and Yuen, 2005), those 
whose GC content is lower may require tRNAs to complement their biochemical requirements. Finally, certain bacteriophages may code for and transfer ARGs in bacteria through transduction (Gunathilaka et al., 2017; Brown-Jaque et al., 2018; Larranaga et al., 2018; Wang et al., 2018). None of the bacteriophages isolated here were found to code for these, which may be a favorable feature if they were to be used in environmental or clinical settings.

\section{CONCLUSION}

We report here a diverse range of novel bacteriophages, LAh1LAh10, which are the first shown to be active against clinical strains of $A$. hydrophila. While these bacteria may survive decontaminating efforts in water by quorum sensing and forming biofilms, bacteriophages offer the potential of an alternative to control their growth in the environment, as well as following human infection. Functionally, the bacteriophages tested here were capable of $A$. hydrophila biofilm disruption.

\section{DATA AVAILABILITY STATEMENT}

The complete genome sequences have been submitted to NCBI GenBank with accession numbers: MK838107, MK838108,

\section{REFERENCES}

Aguirre, A. A., and Tabor, G. M. (2008). Global factors driving emerging infectious diseases. Ann. N. Y. Acad. Sci. 1149, 1-3. doi: 10.1196/annals. 1428.052

Ahmed, W., Huygens, F., Goonetilleke, A., and Gardner, T. (2008). Real-time Pcr detection of pathogenic microorganisms in roof-harvested rainwater in Southeast Queensland, Australia. Appl. Environ. Microbiol. 74, 5490-5496. doi: 10.1128/AEM.00331-08

Anand, T., Vaid, R. K., Bera, B., Singh, J., Barua, S., Virmani, N., et al. (2016). Isolation of a lytic bacteriophage against virulent Aeromonas hydrophila from an organized equine farm. J. Basic Microbiol. 56, 432-437. doi: 10.1002/jobm. 201500318

Azzopardi, E. A., Azzopardi, S. M., Boyce, D. E., and Dickson, W. A. (2011). Emerging gram-negative infections in burn wounds. J. Burn. Care Res. 32, 570-576. doi: 10.1097/BCR.0b013e31822ac7e6

Bai, M., Cheng, Y. H., Sun, X. Q., Wang, Z. Y., Wang, Y. X., Cui, X. L., et al. (2019). Nine novel phages from a plateau lake in southwest china: insights into aeromonas phage diversity. Viruses 11:E615. doi: 10.3390/v11070615

Bailly-Bechet, M., Vergassola, M., and Rocha, E. (2007). Causes for the intriguing presence of trnas in phages. Genome Res. 17, 1486-1495. doi: 10.1101/gr. 6649807

Batra, P., Mathur, P., and Misra, M. C. (2016). Aeromonas spp.: an emerging nosocomial pathogen. J. Lab. Physicians 8, 1-4. doi: 10.4103/0974-2727.176234

Beilstein, F., and Dreiseikelmann, B. (2008). Temperate bacteriophage PhiO18P from an Aeromonas media isolate: characterization and complete genome sequence. Virology 373, 25-29. doi: 10.1016/j.virol.2007.11.016

Brown-Jaque, M., Calero-Caceres, W., Espinal, P., Rodriguez-Navarro, J., Miro, E., Gonzalez-Lopez, J. J., et al. (2018). Antibiotic resistance genes in phage particles isolated from human faeces and induced from clinical bacterial isolates. Int. J. Antimicrob. Agents 51, 434-442. doi: 10.1016/j.ijantimicag.2017.11.014

Burke, V., Robinson, J., Gracey, M., Peterson, D., Meyer, N., and Haley, V. (1984a). Isolation of Aeromonas spp. from an unchlorinated domestic water supply. Appl. Environ. Microbiol. 48, 367-370. doi: 10.1128/aem.48.2.367-370.1984

Burke, V., Robinson, J., Gracey, M., Peterson, D., and Partridge, K. (1984b). Isolation of Aeromonas hydrophila from a metropolitan water supply: seasonal
MK838109, MK838110, MK838111, MK838112, MK838113, MK838114, MK838115, and MK838116.

\section{AUTHOR CONTRIBUTIONS}

JT, HC, and MK: conceptualization. MK, HK, and HC: data collection. MK and TB: genomics. MK, LS, and PL: electron microscope imaging and biofilm. MK, ML, and JT: data analysis. JT, HC, and SP: supervision. $\mathrm{MK}$ and JT: writing - original draft. MK, TB, HC, and JT: writing - review and editing.

\section{ACKNOWLEDGMENTS}

The authors would like to acknowledge the La Trobe University Bio-imaging Facility (La Trobe Institute for Molecular Science) for the TEM images.

\section{SUPPLEMENTARY MATERIAL}

The Supplementary Material for this article can be found online at: https://www.frontiersin.org/articles/10.3389/fmicb. 2020.00194/full\#supplementary-material

correlation with clinical isolates. Appl. Environ. Microbiol. 48, 361-366. doi: 10.1128/aem.48.2.361-366.1984

Cao, Y., Li, S., Wang, D., Zhao, J., Xu, L., Liu, H., et al. (2019). Genomic characterization of a novel virulent phage infecting the Aeromonas hydrophila isolated from rainbow trout (Oncorhynchus mykiss). Virus Res. 273:197764. doi: 10.1016/j.virusres.2019.197764

Chan, K. G., Tan, W. S., Chang, C. Y., Yin, W. F., and Mumahad Yunos, N. Y. (2015). Genome sequence analysis reveals evidence of quorumsensing genes present in aeromonas hydrophila strain M062, Isolated from Freshwater. Genome Announc. 3:e00100-15. doi: 10.1128/genomeA.001 $00-15$

Chow, M. S., and Rouf, M. A. (1983). Isolation and partial characterization of two Aeromonas hydrophila bacteriophages. Appl. Environ. Microbiol. 45, 1670-1676. doi: 10.1128/aem.45.5.1670-1676.1983

Chowdhury, M. A., Yamanaka, H., Miyoshi, S., and Shinoda, S. (1990). Ecology of mesophilic Aeromonas spp. in aquatic environments of a temperate region and relationship with some biotic and abiotic environmental parameters. Zentralbl Hyg Umweltmed 190, 344-356.

Chubaka, C. E., Whiley, H., Edwards, J. W., and Ross, K. E. (2018). A review of roof harvested rainwater in Australia. J. Environ. Public Health 2018, 6471324. doi: 10.1155/2018/6471324

Czaplewski, L., Bax, R., Clokie, M., Dawson, M., Fairhead, H., Fischetti, V. A., et al. (2016). Alternatives to antibiotics-a pipeline portfolio review. Lancet Infect Dis. 16, 239-251. doi: 10.1016/S1473-3099(15)00466-1

Darling, A. C., Mau, B., Blattner, F. R., and Perna, N. T. (2004). Mauve: multiple alignment of conserved genomic sequence with rearrangements. Genome Res. 14, 1394-1403. doi: 10.1101/gr.2289704

Dedrick, R. M., Guerrero-Bustamante, C. A., Garlena, R. A., Russell, D. A., Ford, K., Harris, K., et al. (2019). Engineered bacteriophages for treatment of a patient with a disseminated drug-resistant Mycobacterium abscessus. Nat. Med. 25, 730-733. doi: 10.1038/s41591-019-0437-z

DeNicola, E., Aburizaiza, O. S., Siddique, A., Khwaja, H., and Carpenter, D. O. (2015). Climate change and water scarcity: the case of saudi Arabia. Ann. Glob. Health 81, 342-353. doi: 10.1016/j.aogh.2015. 08.005 
Donlan, R. M., and Costerton, J. W. (2002). Biofilms: survival mechanisms of clinically relevant microorganisms. Clin. Microbiol. Rev. 15, 167-193. doi: 10.1128/cmr.15.2.167-193.2002

Dryden, M., and Munro, R. (1989). Aeromonas septicemia: relationship of species and clinical features. Pathology 21, 111-114. doi: 10.3109/00313028909059546

Dziewit, L., and Radlinska, M. (2016). Two novel temperate bacteriophages co-existing in Aeromonas sp. Arm81 - characterization of their genomes, proteomes and Dna methyltransferases. J. Gen. Virol. 97, 2008-2022. doi: 10. 1099/jgv.0.000504

Forn-Cuni, G., Tomas, J. M., and Merino, S. (2016a). Genome sequence of Aeromonas hydrophila strain Ah-3 (Serotype O34). Genome Announc. 4:e00919-16.

Forn-Cuni, G., Tomas, J. M., and Merino, S. (2016b). Whole-genome sequence of Aeromonas hydrophila strain Ah-1 (Serotype O11). Genome Announc. 4:e00920-16. doi: 10.1128/genomeA.00920-16

Gibb, E. A., and Edgell, D. R. (2007). Multiple controls regulate the expression of mobE, an Hnh homing endonuclease gene embedded within a ribonucleotide reductase gene of phage Aeh1. J. Bacteriol. 189, 4648-4661. doi: 10.1128/jb. 00321-07

Golkar, Z., Bagasra, O., and Pace, D. G. (2014). Bacteriophage therapy: a potential solution for the antibiotic resistance crisis. J. Infect Dev. Ctries 8, 129-136. doi: $10.3855 /$ jidc. 3573

Grissa, I., Vergnaud, G., and Pourcel, C. (2007). Crisprfinder: a web tool to identify clustered regularly interspaced short palindromic repeats. Nucleic Acids Res. 35 , W52-W57.

Gunathilaka, G. U., Tahlan, V., Mafiz, A., Polur, M., and Zhang, Y. (2017). Phages in urban wastewater have the potential to disseminate antibiotic resistance. Int. J. Antimicrob. Agents 50, 678-683. doi: 10.1016/j.ijantimicag.2017.08.013

Hansen, M. F., Svenningsen, S. L., Røder, H. L., Middelboe, M., and Burmølle, M. (2019). Big Impact of the Tiny: bacteriophage-bacteria Interactions in Biofilms. Trends Microbiol. 27, 739-752. doi: 10.1016/j.tim.2019.04.006

Igbinosa, I. H., Igumbor, E. U., Aghdasi, F., Tom, M., and Okoh, A. I. (2012). Emerging Aeromonas species infections and their significance in public health. Sci. World J. 2012:625023.

Janda, J. M., and Abbott, S. L. (2010). The genus Aeromonas: taxonomy, pathogenicity, and infection. Clin. Microbiol. Rev. 23, 35-73. doi: 10.1128/CMR. 00039-09

Jia, B., Raphenya, A. R., Alcock, B., Waglechner, N., Guo, P., Tsang, K. K., et al. (2017). Card 2017: expansion and model-centric curation of the comprehensive antibiotic resistance database. Nucleic Acids Res. 45, D566-D573. doi: 10.1093/ nar/gkw1004

Julia Manresa, M., Vicente Villa, A., Gene Giralt, A., and Gonzalez-Ensenat, M. A. (2009). Aeromonas hydrophila folliculitis associated with an inflatable swimming pool: mimicking Pseudomonas aeruginosa infection. Pediatr. Dermatol. 26, 601-603. doi: 10.1111/j.1525-1470.2009.00993.x

Jun, J. W., Kim, J. H., Shin, S. P., Han, J. E., Chai, J. Y., and Park, S. C. (2013). Protective effects of the Aeromonas phages pAh1-C and pAh6-C against mass mortality of the cyprinid loach (Misgurnus anguillicaudatus) caused by Aeromonas hydrophila. Aquaculture 416, 289-295. doi: 10.1016/j.aquaculture. 2013.09.045

Kazimierczak, J., Wojcik, E. A., Witaszewska, J., Guzinski, A., Gorecka, E., Stanczyk, M., et al. (2019). Complete genome sequences of Aeromonas and Pseudomonas phages as a supportive tool for development of antibacterial treatment in aquaculture. Virol. J. 16:4. doi: 10.1186/s12985-018-1113-5

Larranaga, O., Brown-Jaque, M., Quiros, P., Gomez-Gomez, C., Blanch, A. R., Rodriguez-Rubio, L., et al. (2018). Phage particles harboring antibiotic resistance genes in fresh-cut vegetables and agricultural soil. Environ. Int. 115, 133-141. doi: 10.1016/j.envint.2018.03.019

Laslett, D., and Canback, B. (2004). Aragorn, a program to detect trna genes and tmrna genes in nucleotide sequences. Nucleic Acids Res. 32, 11-16. doi: $10.1093 / \mathrm{nar} / \mathrm{gkh} 152$

Le, T. S., Nguyen, T. H., Vo, H. P., Doan, V. C., Nguyen, H. L., Tran, M. T., et al. (2018). Protective effects of Bacteriophages against Aeromonas hydrophila species causing motile Aeromonas septicemia (Mas) in striped catfish. Antibiotics 7, E16. doi: 10.3390/antibiotics7010016

Lowe, T. M., and Chan, P. P. (2016). trnascan-Se On-line: integrating search and context for analysis of transfer Rna genes. Nucleic Acids Res. 44, W54-W57. doi: 10.1093/nar/gkw413
Malik, D. J., Sokolov, I. J., Vinner, G. K., Mancuso, F., Cinquerrui, S., Vladisavljevic, G. T., et al. (2017). Formulation, stabilisation and encapsulation of bacteriophage for phage therapy. Adv. Colloid. Interface Sci. 249, 100-133. doi: 10.1016/j.cis.2017.05.014

Mateos, D., Anguita, J., Naharro, G., and Paniagua, C. (1993). Influence of growth temperature on the production of extracellular virulence factors and pathogenicity of environmental and human strains of Aeromonas hydrophila. J. Appl. Bacteriol. 74, 111-118. doi: 10.1111/j.1365-2672.1993.tb0 3003.x

Merino, S., Camprubi, S., and Tomas, J. M. (1990a). Isolation and characterization of bacteriophage Pm2 from Aeromonas hydrophila. Fems Microbiol. Lett. 56, 239-244. doi: 10.1111/j.1574-6968.1990.tb13944.x

Merino, S., Camprubi, S., and Tomas, J. M. (1990b). Isolation and characterization of bacteriophage Pm3 from Aeromonas hydrophila the bacterial receptor for which is the monopolar flagellum. Fems Microbiol. Lett. 57, 277-282. doi: 10.1111/j.1574-6968.1990.tb04244.x

Merritt, J. H., Kadouri, D. E., and O'toole, G. A. (2005). Growing and analyzing static biofilms. Curr. Protoc. Microbiol. 1:Unit 1B.1. doi: 10.1002/ 9780471729259.mc01b01s00

Mount, D. W. (2007). Using the basic local alignment search tool (Blast). Csh. Protoc. 2007:dbto17. doi: 10.1101/pdb.top17

Moura, Q., Fernandes, M. R., Cerdeira, L., Santos, A. C. M., De Souza, T. A., Ienne, S., et al. (2017). Draft genome sequence of a multidrug-resistant Aeromonas hydrophila St508 strain carrying $\mathrm{rmtD}$ and blactx-M-131 isolated from a bloodstream infection. J. Glob. Antimicrob. Resist. 10, 289-290. doi: 10.1016/ j.jgar.2017.07.007

Neyts, K., Huys, G., Uyttendaele, M., Swings, J., and Debevere, J. (2000). Incidence and identification of mesophilic Aeromonas spp. from retail foods. Lett. Appl. Microbiol. 31, 359-363. doi: 10.1046/j.1472-765x.2000.00828.x

Nir-Paz, R., Gelman, D., Khouri, A., Sisson, B. M., Fackler, J., Alkalay-Oren, S., et al. (2019). Successful treatment of antibiotic resistant poly-microbial bone infection with bacteriophages and antibiotics combination. Clin. Infect Dis. 69, 2015-2018. doi: 10.1093/cid/ciz222

Picard, B., and Goullet, P. (1987). Seasonal prevalence of nosocomial Aeromonas hydrophila infection related to aeromonas in hospital water. J. Hosp. Infect. 10, 152-155. doi: 10.1016/0195-6701(87)90141-1

Rasmussen-Ivey, C. R., Figueras, M. J., Mcgarey, D., and Liles, M. R. (2016). Virulence Factors of Aeromonas hydrophila: in the wake of reclassification. Front. Microbiol. 7:1337. doi: 10.3389/fmicb.2016.01337

Saha, D., and Mukherjee, R. (2019). Ameliorating the antimicrobial resistance crisis: phage therapy. Iubmb. Life 71, 781-790. doi: 10.1002/iub. 2010

Schmidt, C. (2019). Phage therapy's latest makeover. Nat. Biotechnol. 37, 581-586. doi: 10.1038/s41587-019-0133-z

Shen, C. J., Liu, Y. J., and Lu, C. P. (2012). Complete genome sequence of Aeromonas hydrophila Phage Cc2. J. Virol. 86:10900. doi: 10.1128/JVI.018 82-12

Sinclair, H. A., Heney, C., Sidjabat, H. E., George, N. M., Bergh, H., Anuj, S. N., et al. (2016). Genotypic and phenotypic identification of Aeromonas species and CphA-mediated carbapenem resistance in Queensland, Australia. Diagn. Microbiol. Infect Dis. 85, 98-101. doi: 10.1016/j.diagmicrobio.2016. 02.005

Talagrand-Reboul, E., Jumas-Bilak, E., and Lamy, B. (2017). The social life of aeromonas through biofilm and quorum sensing systems. Front. Microbiol. 8:37. doi: 10.3389/fmicb.2017.00037

Tan, W. S., Yin, W. F., and Chan, K. G. (2015a). Insights into the quorum-sensing activity in Aeromonas hydrophila strain M013 as revealed by whole-genome sequencing. Genome Announc. 3:e01372-14. doi: 10.1128/genomeA.013 72-14

Tan, W. S., Yin, W. F., Chang, C. Y., and Chan, K. G. (2015b). Whole-genome sequencing analysis of quorum-sensing Aeromonas hydrophila Strain M023 from freshwater. Genome Announc. 3:e01548-14. doi: 10.1128/genomeA.0154814

Vally, H., Whittle, A., Cameron, S., Dowse, G. K., and Watson, T. (2004). Outbreak of Aeromonas hydrophila wound infections associated with mud football. Clin. Infect. Dis. 38, 1084-1089. doi: 10.1086/382876

Varela, A. R., Nunes, O. C., and Manaia, C. M. (2016). Quinolone resistant Aeromonas spp. as carriers and potential tracers of acquired antibiotic resistance 
in hospital and municipal wastewater. Sci. Total Environ. 542, 665-671. doi: 10.1016/j.scitotenv.2015.10.124

Vincent, A. T., Paquet, V. E., Bernatchez, A., Tremblay, D. M., Moineau, S., and Charette, S. J. (2017). Characterization and diversity of phages infecting Aeromonas salmonicida subsp. salmonicida. Sci. Rep. 7:7054. doi: 10.1038/ s41598-017-07401-7

Wang, J. B., Lin, N. T., Tseng, Y. H., and Weng, S. F. (2016). Genomic characterization of the novel Aeromonas hydrophila phage ahpl suggests the derivation of a new subgroup from phikmv-like family. PloS One 11:e0162060. doi: 10.1371/journal.pone.0162060

Wang, Q., Zeng, X., Yang, Q., and Yang, C. (2018). Identification of a bacteriophage from an environmental multidrug-resistant $E$. coli isolate and its function in horizontal transfer of Args. Sci. Total Environ. 639, 617-623. doi: 10.1016/j. scitotenv.2018.05.213

World Health Organisation [WHO] (2014). Antimicrobial Resistance: Global Report on Surveillance 2014. Geneva: WHO.

Xia, X., and Yuen, K. Y. (2005). Differential selection and mutation between dsdna and ssdna phages shape the evolution of their genomic At percentage. Bmc Genet. 6:20.
Yu, H. B., Kaur, R., Lim, S., Wang, X. H., and Leung, K. Y. (2007). Characterization of extracellular proteins produced by Aeromonas hydrophila Ah-1. Proteomics 7, 436-449. doi: 10.1002/pmic.200600396

Yuan, S., Chen, L., Liu, Q., Zhou, Y., Yang, J., Deng, D., et al. (2018). Characterization and genomic analyses of Aeromonas hydrophila phages AhSzq-1 and AhSzw-1, isolates representing new species within the T5virus genus. Arch. Virol. 163, 1985-1988. doi: 10.1007/s00705-018-3805-y

Conflict of Interest: The authors declare that the research was conducted in the absence of any commercial or financial relationships that could be construed as a potential conflict of interest.

Copyright (C) 2020 Kabwe, Brown, Speirs, Ku, Leach, Chan, Petrovski, Lock and Tucci. This is an open-access article distributed under the terms of the Creative Commons Attribution License (CC BY). The use, distribution or reproduction in other forums is permitted, provided the original author(s) and the copyright owner(s) are credited and that the original publication in this journal is cited, in accordance with accepted academic practice. No use, distribution or reproduction is permitted which does not comply with these terms. 